\title{
Proposta de Downlink para uma Rede Secundária Baseada no Modelo Underlay de Rádio Cognitivo
}

\author{
Ricardo Carvalho Pereira e Richard Demo Souza
}

\begin{abstract}
Resumo-Apresentamos uma proposta para o downlink de uma rede de dados sem fio do tipo fixo-móvel operando como um sistema secundário segundo o modelo underlay de rádio cognitivo. O sistema secundário proposto é inserido no mesma região de uma rede primária celular baseada em FDD-CDMA operando nos padrões IS-95, Rel99 ou HSDPA, além de utilizar a mesma banda de freqüências e operar ao mesmo tempo. Utilizamos técnicas de manipulação do feixe das antenas da estação base secundária de modo a melhorar o desempenho sem afetar a rede primária. Mostramos que o sistema secundário pode fornecer taxas aos usuários próximas daquelas de um sistema operando como primário.
\end{abstract}

Palavras-Chave-Rádio cognitivo, Redes Sem Fio, Underlay, Formatação de Feixe de Antenas.

Abstract-We present a proposal for the downlink of a wireless data network with a fixed base station operating in the same geographic region of a primary cellular wireless network using FDD-CDMA which can be based on IS-95, Rel99 or HSDPA. Besides, the secondary network operates in the same band and at the same time than the primary network. We utilize orthogonal beamforming antenna techniques in order to improve capacity without harming the primary network performance. We show that the secondary system can provide user bit rates close to those provided by a primary system.

Keywords-Cognitive Radio, Wireless Networks, Underlay, Antenna Beamforming.

\section{INTRODUÇÃO}

Desde a introdução das primeiras redes sem fio, a demanda por mais capacidade tem aumentado continuamente. Algumas redes comerciais já migraram de uma rede dominada por serviços de voz para serviços de dados. O volume de tráfego de dados transportado por redes de comunicações sem fio é imenso. Em 2008 o aumento atingiu um fator de cinco. As redes das maiores operadoras estão transportando volumes de dados da ordem de 5 a 6 TBytes/dia [1]. O desenvolvimento das redes sem fio que suportam serviços de dados têm encontrado um limitante importante que é a escassez de espectro de freqüências para suportar mais capacidade. Além disto, a alocação de espectro de frequiências exclusivas por serviço fez com que a utilização de grande parte do espectro seja tão baixa quanto $15 \%$ [2], [3]. Obter uma alta utilização do espectro é, hoje, um dos objetivos de pesquisa mais críticos no projeto de sistemas de comunicações sem fio [4]. Por isso, há um crescente interesse no desenvolvimento de métodos eficientes para o gerenciamento e compartilhamento do espectro [5].

Neste artigo, vamos endereçar este problema da escassez do espectro através da aplicação de um novo paradigma de comunicação, o modelo rádio cognitivo. No princípio, rádios

R. C. Pereira e R. D. Souza, CPGEI, UTFPR, Curitiba-PR, Brasil, e-mail: rcapereira@timbrasil.com.br, richard@utfpr.edu.br. cognitivos foram vistos como uma solução promissora para o problema da ocupação intensa do espectro [6]. A idéia básica deste esquema é explorar a característica de baixa utilização de bandas do espectro licenciado, para assim acomodar comunicações secundárias (não licenciadas) de dispositivos sem fio sem atrapalhar a comunicação dos usuários primários (licenciados) do espectro de frequiências.

$\mathrm{O}$ conceito de rádio cognitivo pode ser implementado de maneiras diferentes, conhecidas como interweave, overlay e underlay [7], [8], sendo que, em todas há a preocupação de o desempenho do usuário primário do espectro não ser afetado pelo usuário secundário. O modo interweave foi originalmente proposto por Mitola [6], onde os usuários secundários exploram a parte do espectro que está temporariamente desocupada pelos usuários primários. O modelo overlay permite transmissões simultâneas do primário e do secundário [7]. O esquema consiste no usuário secundário poder usar parte de sua potência para sua própria comunicação e o restante da potência pode ser utilizada para auxiliar o primário.

No modelo underlay os usuários secundários transmitem simultaneamente com os primários, mas protegendo as comunicações dos usuários primários através da garantia de uma máscara espectral no sinal secundário, de maneira que a interferência gerada esteja abaixo do chão de ruído ou de um limiar aceitável [7], [9]. Uma forma de controlar a degradação é a noção da temperatura de interferência [5]. Neste cenário, a temperatura de interferência do receptor primário deve ser mantida em um nível que satisfaça a qualidade de serviço desejada pelo primário. Esta imposição sobre a interferência aceitável nos receptores primários estabelece vários desafios para implementar o modelo underlay de rádio cognitivo, uma vez que o sistema secundário tem que conhecer: i) a máxima temperatura de interferência admitida pelos receptores primários na redondeza; ii) a temperatura de interferência atual; e iii) como sua potência de transmissão será convertida em potência recebida no receptor primário, o que significa conhecer o estado do canal entre o dispositivo transmissor secundário e o receptor primário.

Uma das propostas para reduzir a interferência é o emprego de um conjunto de antenas adaptativas no sistema secundário de modo que o feixe das antenas possa ser formatado. Taranto et al [10] apresentaram um sistema secundário sem fio estruturado em malha para comunicação em curta distância onde os dispositivos possuem duas ou três antenas. Este sistema opera dentro da área de cobertura de um sistema sem fio primário de médio ou grande alcance. De modo a diminuir a interferência, o feixe das antenas do transmissor secundário é produzido de tal forma que o nulo sempre estará apontando para a direção do receptor primário. Este sistema tem o inconveniente de 
empregar duas ou mais antenas no terminal do usuário e a limitação da quantidade de nulos caso o número de receptores primários for superior a dois.

Recentemente, Kim et al. [11] propuseram que pares de nós secundários pudessem comunicar dentro da área de cobertura de um sistema celular primário operando em CDMA. Nesta proposta, tanto a taxa dos usuários secundários quanto sua potência são controladas de forma a atender dois requisitos: i) a qualidade de serviço do enlace secundário em termos de razão sinal ruído e mínima taxa de dados; ii) limite de interferência tolerável nos receptores primários. Aqui, levase em consideração a soma das contribuições de todos os transmissores secundários na temperatura de interferência do receptor primário e a questão de justiça entre os usuários secundários. Para isso, supõe-se que o sistema secundário dispõe de um controlador central que obtém freqüentemente a informação sobre a soma de interferência no primário, o que é complexo para realização prática.

Kwon et al. [12] propuseram um esquema onde o sistema secundário tem a mesma estrutura do sistema primário, qual seja, operam com usuários sem fio e estações base fixas. Os autores introduziram a manipulação da formatação do feixe do conjunto de antenas empregadas na estação base secundária de modo a cancelar a interferência no usuário primário. $\mathrm{O}$ esquema busca maximizar a soma das taxas oferecidas a todos os usuários secundários. Proposta semelhante é encontrada em [13], onde a cooperação entre os sistemas primário e secundário é explorada.

A diferença da proposta deste trabalho é que a banda de freqüências do downlink do sistema secundário opera na banda de uplink do sistema primário. Desta forma, o par interferidorinterferido que afeta o primário é constituído pela estação base secundária e pela estação base primária. Aplicamos a formatação do feixe das antenas na estação base secundária, de modo a cancelar a interferência causada na estação base primária, através da metodologia de ortogonalização por Gram-Schmidt baseado na informação do estado do canal. Como resultado, e principal contribuição, mostramos que o sistema secundário pode fornecer taxas aos usuários próximas daquelas fornecidas por um sistema operando como primário.

O restante deste artigo é estruturado da seguinte maneira. Na Seção II apresentamos o cenário do sistema. Na Seção III discutimos sobre o método de manipulação do feixe, enquanto que na Seção IV introduzimos os parâmetros do sistema e a soma de interferência nos usuários secundários. A Seção $\mathrm{V}$ traz os resultados numéricos que mostram o potencial de capacidade do sistema secundário sob várias condições, ao passo que a Seção VI conclui o artigo.

\section{Sistema SECUNDÁRIO}

O sistema secundário é do tipo fixo-móvel, onde a estação base é fixa e suas antenas estão localizadas acima do nível médio dos prédios e os usuários são móveis e estão próximos ao solo. A proposta restringe-se somente ao downlink deste sistema que opera na mesma banda de frequências de uplink do sistema primário. A banda de uplink do sistema secundário deve operar com faixa própria ou na banda ISM e não é o escopo deste trabalho. Escolheu-se o sistema de topologia fixomóvel devido ao apelo comercial e pelo fato destas poderem ser empregadas pela própria detentora da rede primária para aumentar a oferta de capacidade na mesma localização.

A escolha da banda de downlink operando na faixa de uplink do sistema primário traz várias vantagens que são: i) melhor controle das manipulações do feixe das antenas, uma vez que o par interferidor-interferido é fixo o que diminui a complexidade do algoritmo de estimação de canal e manipulação do feixe; ii) a quantidade de cancelamento de interferência necessária na estação base secundária é limitada ao número de estações base primárias e não à quantidade de usuários primários como proposto em [12], o que reduz a quantidade de elementos de antena necessários; iii) a banda de uplink do sistema primário é menos utilizada em relação ao downlink uma vez que o sistema primário opera com padrões baseados em FDD e o volume de tráfego de dados tem mostrado ser até quatro vezes maior no downlink do que no uplink; iv) não há exigências de múltiplas antenas no equipamento do usuário secundário porque a manipulação do feixe é feita somente na estação base secundária; v) os usuários secundários só recebem interferências externas provenientes dos transmissores dos usuários primários que operam próximos ao solo. Isto traz uma vantagem do ponto de vista de atenuação na propagação do sinal em ambientes urbanos, devido à baixa altura de ambos equipamentos; vi) o controle do algoritmo de justiça de taxa para os secundários é centralizado pela estação base secundária, o que evita o problema de disputa por banda entre os usuários secundários.

A técnica de múltiplo acesso da estação base secundária é DS-CDMA (do inglês Direct Spread - Code Division Multiple Access) que é a mesma empregada no sistema primário. Assim, destacamos as seguintes vantagens: i) é a forma mais apropriada de interferir no sistema primário, pois, o sinal interferente é similar ao sinal interferente vindo de outros usuários do próprio sistema primário; ii) da mesma forma, o usuário lida melhor com a interferência vinda do sistema primário por ser similar à interferência do próprio sistema. $\mathrm{Ou}$ seja, a interferência pode ser intercambiada com capacidade. A taxa do usuário secundário decresce com o aumento da interferência até a impossibilidade de se comunicar; iii) o sistema primário pode negociar sua baixa utilização no uplink para permitir um aumento no limiar de interferência, desta forma, o sistema secundário pode aumentar sua potência de transmissão e, conseqüentemente, aumentar a taxa ou a cobertura do sistema secundário.

Muito embora possa ser generalizado, o modelo específico para a investigação neste trabalho é o proposto na Figura 1. A estação base secundária está localizada no centro da figura e é projetada com 4 setores com abertura horizontal de $90^{\circ}$ e azimute na direção da estação base primária. Por exemplo, o primeiro setor da estação base secundária tem seu azimute na direção $45^{\circ}$ Norte Verdadeiro e aponta diretamente para a estação base primária nomeada de NE (Nordeste). Desta forma, cada setor da estação secundária tem que gerar um nulo baseado na informação do estado do canal entre a estação base primária e a secundária. A obtenção desta informação pode ser conseguida por cooperação ou pela medida da piloto enviada 


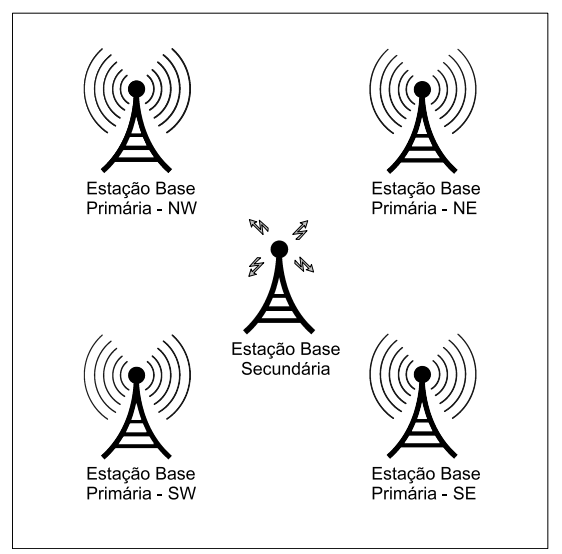

Fig. 1. Sistema secundário operando na mesma região que o sistema primário.

no downlink da estação base primária. Os usuários primários e secundários estão distribuídos uniformemente na região de cobertura de suas estações base.

\section{MANipUlaÇÃo do FeiXe dAS ANTENAS}

Apesar de haver técnicas de manipulação do feixe onde é possível direcioná-lo para os usuários que se deseja transmitir e apontar mínimos para os receptores interferidos, estas técnicas não rejeitam completamente o sinal [14]. A opção por um método de manipulação de feixe ortogonal permite, teoricamente, cancelar completamente a interferência. Desta forma, optamos por projetar um feixe ortogonal ao canal entre a estação base secundária e cada uma das estações base primárias, onde assumimos que a estação base secundária tem $Z$ elementos de antena por setor, enquanto a estação base primária tem um único elemento de antena.

A determinação de cada um destes feixes é feita de acordo com o método de Gram-Schmidt, descrito por exemplo em [12], aqui omitido por falta de espaço. O resultado final é que, para cada um dos $L$ setores da estação base secundária, é determinado o vetor $\mathbf{w}_{1}$, de comprimento $(Z \times 1)$, com os pesos para a formatação do feixe daquele setor. Se o canal entre a estação base secundária e a $j$-ésima estação primária naquele setor seja dado pelo vetor $\mathbf{g}_{\mathbf{j}, \mathbf{l}}$, de comprimento $(Z \times 1)$, então:

$$
\mathbf{g}_{\mathbf{j}, \mathbf{l}}{ }^{H} \mathbf{w}_{\mathbf{l}}=0
$$

onde o sobrescrito ${ }^{H}$ denota o conjugado transposto. Desta forma, a transmissão da estação base secundária não vai interferir na recepção da estação base primária, desde que se obtenha o vetor $\mathbf{g}_{\mathbf{j}, \mathbf{l}}$ sem erro. Além disto, todo o processo de manipulação do feixe das antenas está concentrado na estação base secundária.

\section{Parâmetros do Sistema Proposto}

Consideramos $J=4$ células primárias com $K$ usuários primários espalhados uniformemente pela região. A escolha por qual célula o usuário primário acessa o serviço é baseada na menor distância. A quantidade de usuários primários servidos por uma célula $J$ é limitada pelo valor mínimo da $S I R_{p}$ (Relação Sinal Interferência) requerida pelo usuário primário. Há $L=4$ células (setores) secundárias localizadas em uma única estação base. Cada célula é formada por um setor de abertura horizontal de $90^{\circ}$ e com azimutes $\left\{45^{\circ}, 135^{\circ}, 225^{\circ}, 315^{\circ}\right\}$. O sistema atende $M$ usuários secundários que são servidos pelo setor que irradia para sua posição. A escolha de usar uma célula para cada direção da estação do sistema primário se deve pela facilidade de gerar o feixe com o nulo no receptor da estação primária. Além do mais, como o sistema secundário é baseado em DS-CDMA, há um ganho de capacidade por reutilizar a mesma freqüência.

A interferência percebida pelo $m$-ésimo usuário secundário, causada pelas transmissões dos usuários primários, é:

$$
N_{m}=\sum_{k=1}^{K} \rho_{k} P_{k} g_{k, m}, \quad m=1,2, \ldots, M
$$

onde $\rho_{k} \in\{0,1\}$ representa a atividade do $k$-ésimo usuário primário, $g_{k, m}$ é o ganho do canal entre o $k$-ésimo usuário primário e o $m$-ésimo usuário secundário, $P_{k}$ é a potência de transmissão do $k$-ésimo usuário primário associado à estação base $j$ :

$$
P_{k}=\frac{P_{r}}{g_{k, j}},
$$

onde $g_{k, j}$ é o ganho do canal entre o $k$-ésimo usuário e sua estação base $j$. A potência $P_{r}$ requerida num sistema CDMA varia de acordo com o tráfego do primário [15], por isto derivamos a equação de $P_{r}$ baseada na equação da relação sinal interferência $S I R_{p}$ vista na estação base para cada usuário:

$$
P_{r}=\frac{S I R_{p} \frac{R}{B} B N_{0}+I_{j}}{1-S I R_{p} \frac{R}{B}(1+f)(K-1) \bar{\rho}},
$$

onde $R$ é a taxa em bps do primário, $B$ é a largura de banda do sistema, $N_{0}$ é a densidade espectral de ruído, $f$ é o fator de reuso de frequência, $\bar{\rho}$ é o fator de atividade médio do primário, e $I_{j}$ é a interferência causada pela estação base secundária. Aqui, $I_{j}$ representa uma possível ineficiência da manipulação do feixe. Caso obtenha-se o projeto do feixe perfeitamente ortogonal ao canal entre a estação base secundária e a estação base primária, então $I_{j}=0$.

Podemos escrever a relação sinal interferência percebida pelo $m$-ésimo usuário secundário como:

$$
\mu_{m}=\frac{B}{R_{m}} \frac{\mathbf{g}_{\mathbf{m}, \mathbf{l}}{ }^{H} \mathbf{w}_{\mathbf{l}} P_{m}}{\sum_{i=1, i \neq m}^{M} \mathbf{g}_{\mathbf{i}, \mathbf{l}}{ }^{H} \mathbf{w}_{\mathbf{l}} P_{i}+B N_{0}+N_{m}},
$$

onde $\mathbf{g}_{\mathbf{m}, \mathbf{l}}$ é o vetor ${ }^{1}$ canal entre o $m$-ésimo usuário secundário e o setor de sua estação base servidora $l$, w é o vetor resultante do processo de manipulação do feixe das antenas usado no setor $l, P_{m}$ é a potência de transmissão da estação base secundária dedicada para o usuário secundário $m, P_{i}$ é a potência de transmissão da estação base secundária dedicada para os outros usuários secundários servidos pela estação base, e $R_{m}$ representa a taxa associada ao usuário secundário.

\footnotetext{
${ }^{1}$ Note que apenas a estação base secundária possui mais de um elemento de antena ( $Z$ elementos por setor). Por este motivo, apenas os ganhos dos canais que envolvem a estação base secundária que são representados por vetores.
} 
TABELA I

PARÂMETRos UilizAdos NAS SimulaçÕES

\begin{tabular}{||l|c||}
\hline \hline Parâmetros & Valores \\
\hline Células Primárias $J$ & 4 \\
Células Secundárias $L$ & 4 \\
Freq. Central Canal $f_{c}$ & $2,1 \mathrm{GHz}$ \\
Largura de Faixa $B$ & $3,75 \mathrm{MHz}$ \\
Desvio Padrão Sombreamento $\sigma$ & $6 \mathrm{~dB}$ \\
Densidade Espec. de Ruído $N_{o}$ & $4.10^{-21}$ \\
Taxa Primário $R$ & $10 \mathrm{kbps}$ \\
Régua de Taxa $\left(R_{m}\right) \times 10 \mathrm{kbps}$ & {$[1,2,4,8,16,32,64,128,356]$} \\
Régua de SIR $\left(\mu_{m}\right) \mathrm{dB}$ & {$[6,9,12,15,18,21,24,27,30]$} \\
Pot. Máxima Primário & $1 \mathrm{~W}$ \\
Pot. Estação Base Secundária & $10 \mathrm{~W}$ \\
$S I R_{p}$ Taxa de 10 kbps & $6 \mathrm{~dB}$ \\
Fator de Reuso de Frequência & 0,5 \\
\hline
\end{tabular}

O modelo de perda de propagação utilizado para gerar os ganhos do canal é o modelo de Hata [15], acrescido de dois fatores que representam o desvanecimento $(\alpha)$ e uma variação do sinal por sombreamento $\left(\Gamma_{\sigma}\right)$. O ganho do canal é então dado por:

$$
g=\frac{\bar{G}}{\alpha \cdot 10^{\Gamma_{\sigma / 10}}}
$$

onde $\alpha$ tem distribuição Rayleigh com média unitária e $\Gamma_{\sigma}$ é uma variável Gaussiana com média zero e desvio padrão $\sigma$. O ganho médio do canal é, segundo o modelo de Hata:

$$
\begin{array}{r}
\bar{G}(d B)=-\left[69,55+26,16 \log _{10} f_{c}-13.82 \log _{10} h_{1}-\right. \\
\left.+a\left(h_{2}\right)+\left(44,9-6,55 \log _{10} h_{1}\right) \log _{10} d\right]
\end{array}
$$

onde $h_{1}$ e $h_{2}$ são as alturas das antenas de transmissão e recepção em metros, respectivamente, $d$ é a distância do enlace em $\mathrm{km}, f_{c}$ é a freqüência central em $\mathrm{MHz}$ e

$$
a\left(h_{2}\right)=3,2\left(\log _{10} 11,75 h_{2}\right)^{2}-4,97
$$

é o fator de correção do ganho da altura da antena que depende do ambiente, onde consideramos o caso para grandes cidades.

No cenário desta proposta vamos ter dois tipos de ganho de canal distintos: um entre a estação base e o usuário com alturas de $40 \mathrm{~m}$ e $1,5 \mathrm{~m}$, respectivamente; e entre dois usuários, o primário e o secundário com alturas de $4,0 \mathrm{~m}$ e $1,5 \mathrm{~m}$. O modelo de Hata é bem aceito para o primeiro caso, mas não o é para o segundo, motivo pelo qual definimos a altura do transmissor em 4,0 m que é o limite sugerido do modelo. A diferença no ganho do canal para os dois cenários é de 13,8 dB. Investigamos outros modelos baseados em estações base do tipo micro com alturas em torno de $10 \mathrm{~m}$, mas requerem vários parâmetros, como o conhecimento se o enlace é em linha de visada, a densidade de prédios, a altura relativa da antena em relação aos prédios e o ângulo de incidência do sinal em relação ao alinhamento das vias [15], [16]. Por motivo de simplicidade, adotamos o Hata para os dois casos.

Os outros parâmetros são dados na Tabela I. A densidade espectral de ruído é baseada na temperatura de referência de $290 K$. A área da região do sistema foi limitada em $4 \mathrm{~km}^{2}$ devido ao limite imposto pela perda de percurso máxima na célula primária na condição de capacidade máxima. Ou seja, acima deste valor, os usuários primários teriam que exceder a potência máxima de $1 \mathrm{~W}$.

A equação da taxa atingível pelo usuário secundário foi obtida baseada em (5) considerando uma taxa básica de $\mathrm{R}=10$ kbps. Então, obtém-se o valor de $\mu_{m}$ para cada usuário. Este valor é comparado com a régua de $\mu$ do secundário, onde atribui-se o valor da régua (Tabela I ) mais próximo em direção a zero. Para este valor de $\mu_{m}$, está relacionada uma taxa atingível no padrão CDMA. Por exemplo, se o resultado de (5) for $13 \mathrm{~dB}$, o valor tomado na régua é $12 \mathrm{~dB}$ e sua taxa será $40 \mathrm{kbps}$. Ou seja, seria equivalente a ter quatro usuários com taxa de $10 \mathrm{kbps}$ para uma SIR de $6 \mathrm{~dB}$.

A estação base secundária transmite sempre com potência máxima de forma a prover a máxima capacidade em taxa para os usuários. A potência é dividida para os usuários uniformemente. Deixamos o estudo de técnicas de alocação otimizada de recursos para diferentes objetivos como taxa máxima do sistema, justiça com os usuários e garantia de QoS para o desenvolvimento futuro deste trabalho.

Com o propósito de averiguar o desempenho do sistema secundário, definimos um fator de eficiência (FE) que compara as taxas distribuídas aos usuários com um sistema CDMA de referência operando livre de interferência de outros sistemas. Assim, para o sistema de referência, consideramos $N_{m}=0$ em (5) e obtemos as taxas da mesma forma.

\section{RESUltAdos NumÉRICOS}

As simulações foram feitas considerando diferentes números $K$ de usuários primários e $M$ de secundários. Para cada par de valores $(K, M)$ foram geradas 10 topologias aleatórias. Em cada uma das topologias, além do posicionamento dos usuários, também é sorteada 100 realizações dos canais envolvendo os usuários primários e secundários. Ou seja, um total de 1000 sorteios para cada par $(K, M)$. Adotamos o fator de atividade do primário como $\rho_{k}=1$ porque o efeito de $\rho_{k}<1$ pode ser observado comparando quantidades de usuários primários distintas. Por exemplo, se $\rho_{k}=0,5$ como em [11], o FE para um dado $K$ é obtido observando o resultado para $K / 2$ quando $\rho_{k}=1$. Além do mais, a área da região quadrada que engloba todas as células em questão é de $X^{2}=4 \mathrm{~km}^{2}$, enquanto o raio da célula secundária é de $X / 4$, a menos que especificado de outra forma.

A Figura 2 mostra o FE para algumas quantidades de usuários secundários. Quanto maior a quantidade de usuários secundários melhor é o FE. O FE permanece acima de 0,95 para $M>20$ e $K<100$, sendo portanto bastante alto. A variabilidade do FE pode ser verificada na Figura 3, onde são mostrados o mínimo e o máximo de FE nas 1000 realizações para cada par $(K, M)$. A explicação para a diferença dependendo do número de usuários secundários é devido à proporção entre os termos $\sum_{i=1, i \neq m}^{M} \mathbf{g}_{\mathbf{i}, 1}{ }^{H} \mathbf{w}_{\mathbf{l}} P_{i} \mathrm{e}$ $N_{m}$ em (5). Quanto menor o número de usuários secundários, $N_{m}$ é mais influente no resultado da taxa. A recíproca também é observada. Quando o número de secundários aumenta, o primeiro termo fica mais relevante em relação ao termo $N_{m}$.

Usamos valores de $K$ até 300 nas simulações de modo a permitir que todas as células primárias operassem no máximo 


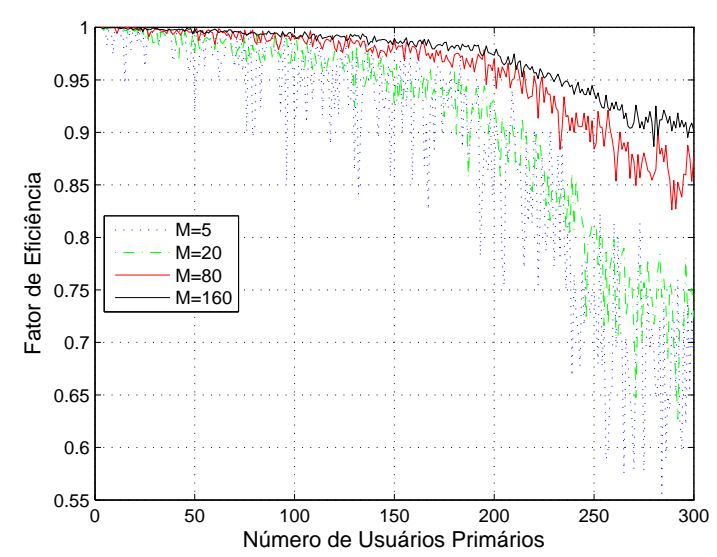

Fig. 2. Fator de Eficiência médio do sistema secundário.
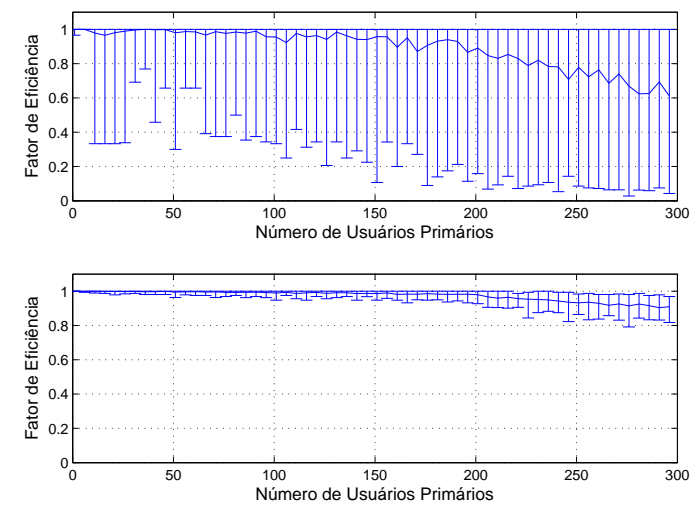

Fig. 3. Valores médio, mínimo e máximo do Fator de Eficiência para 10 diferentes topologias dos pares $(M=5, K)$ e $(M=160, K)$.

de sua capacidade de $K=63$ usuários por célula, ou $K=$ 252 em toda a região. Como a distribuição dos usuários é uniforme, é preciso sortear um número superior de usuários. Se a quantidade de usuários por célula ultrapassar o limite de $K=63$, o excedente de usuários é descartado. Por isso, observa-se nas Figuras 2 e 3 que a curva tende a manter o mesmo comportamento após a condição de usuários máximos por célula ser atingida.

A Figura 4 mostra a taxa oferecida pelo sistema secundário mesmo sendo interferido pelo sistema primário. É possível oferecer taxas médias de algumas unidades de Mbps com uma banda de $B=3,75 \mathrm{MHz}$. Isto mostra a potencialidade desta proposta em atacar o problema da escassez de espectro para redes de dados sem fio.

As Figuras 5 e 6 apresentam a taxa média por usuário secundário, a percentagem do tempo que o usuário experimenta taxa zero, ou impossibilidade de se comunicar, e a distribuição de taxas obtidas pelos usuários. Observe que para pequenas quantidades $M$, o usuário consegue atingir taxas de centenas de kbps. Para grandes quantidades de $M$ os resultados mostram que as taxas são menores porque adotamos a mesma porção de potência para todos os usuários secundários. Se introduzirmos um algoritmo de alocação de recursos,



Fig. 4. Taxa total média fornecida pelo sistema secundário.

então poderíamos destinar mais capacidade do sistema para alguns usuários permitindo que estes atinjam taxas maiores em detrimento de outros. O percentual do tempo com taxa zero mostra que com esta estratégia de alocação e sob interferência do sistema primário, os usuários secundários não ficam sem comunicar por mais de $10 \%$ do tempo para todos os cenários. Porém, note que esta é uma medida do ponto de vista do sistema. Ou seja, um usuário pode ficar o tempo todo sem comunicar, enquanto vários outros nunca experimentam uma interrupção.
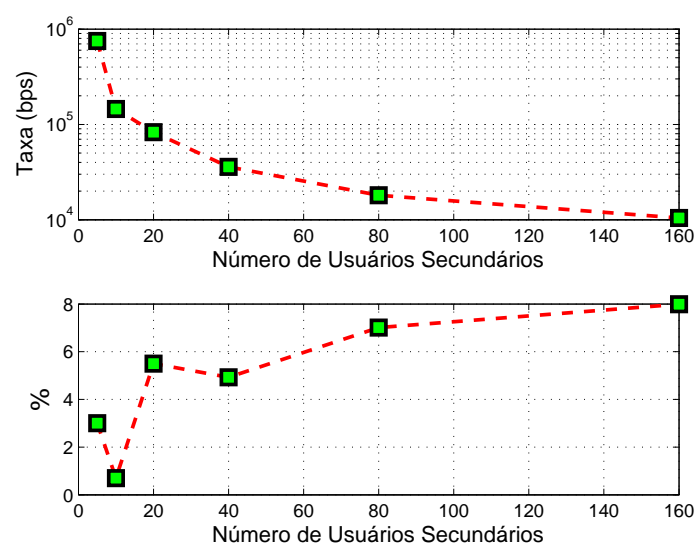

Fig. 5. Taxa média do secundário e a \% do tempo com taxa zero.

Na Figura 7 (a) apresentamos a influência do tamanho da célula secundária no FE. Quanto maior o raio da célula secundária menor é o FE. A simulação considera $M=40$. A Figura 7 (b) mostra o efeito na taxa média do sistema. De novo, o impacto negativo se deve à proporção de $N_{m}$ em (5) em relação ao denominador. Quanto maior a distância, menor é o ganho do canal $\mathbf{g}_{\mathbf{i}, 1}$ o que aumenta a influência de $N_{m}$.

Caso haja erro na estimação do canal entre estação base secundária e estação base primária, então a manipulação do feixe das antenas não será totalmente eficaz. Ou seja, $I_{j}>0$ em (4), e o sistema secundário geraria alguma interferência no sistema primário. Para contornar esta situação, uma saída seria 



Fig. 6. Distribuição das taxas do usuário secundário para os cenários dos pares $(M=5, K),(M=20, K)$ e $(M=80, K)$.

reduzir a potência de transmissão da estação base secundária de forma a controlar a interferência na estação base primária. A Figura 8 mostra que, mesmo com atenuação de $20 \mathrm{~dB}$ na potência de transmissão da estação base secundária, ainda obtemos altos valores de FE.
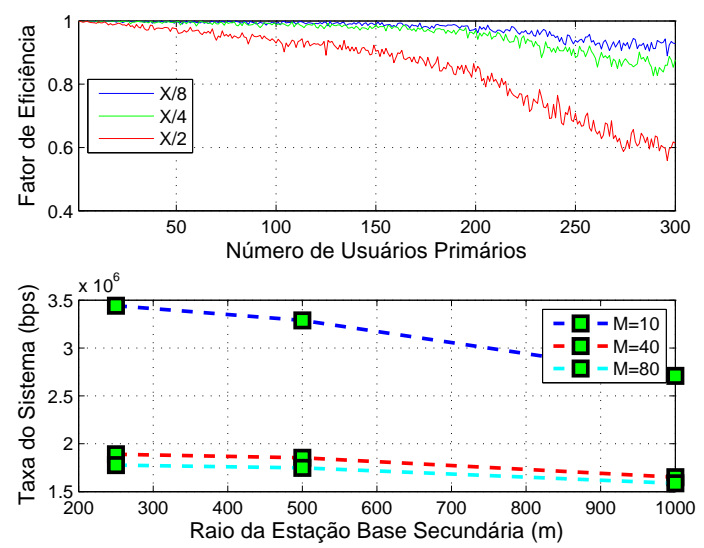

Fig. 7. Efeito do raio da célula no Fator de Eficiência e na taxa total média do sistema secundário.

\section{COMENTÁRIOS FINAIS}

Propusemos um projeto de downlink para uma rede sem fio introduzida numa mesma região de uma rede primária, operando na mesma banda e ao mesmo tempo. A proposta é baseada no modelo underlay de rádio cognitivo que permite a coexistência de duas redes desde que o secundário não afete o desempenho do primário. O método proposto faz o controle de interferência através da técnica de manipulação do feixe das antenas da estação base secundária, além de explorar a característica de propagação entre dois equipamentos próximos do solo como um fator amenizante da interferência sofrida pelo secundário. Investigamos o desempenho da rede secundária através das taxas atingidas pelo sistema e pelos usuários, chegando a unidades de Mbps e centenas de kbps, respectivamente, sem afetar o desempenho do sistema primário.


Fig. 8. Efeito da ineficiência da manipulação do feixe no Fator de Eficiência e na taxa total média do sistema secundário. 'Att' é a atenuação da potência de transmissão da estação base secundária.

\section{AGRADECIMENTOS}

Este trabalho foi financiado em parte pelo $\mathrm{CNPq}$, através dos processos 472977/2007-5 e 303181/2007-9.

\section{REFERÊNCIAS}

[1] K. Bogineni et al., "LTE Part II: Radio access," IEEE Communications Magazine, vol. 47, no. 4, pp. 40-42, Apr. 2009.

[2] Federal Communications Commission. Facilitating opportunities for flexible, efficient and reliable spectrum use employing cognitive radio technologies, notice of proposed rule making and order. FCC 03-322. Dec. 2003.

[3] M. Mchenry, "Report on spectrum occupancy measurements", Shared Spectrum Company, http://www.sharedspectrum.com/?section=nsummary.

[4] L. Le and E. Hossain, "Resource allocation for spectrum underlay in cognitive radio networks," IEEE Transactions on Wireless Communications, vol. 7, no. 12, pp. 5306-5315, Dec. 2008.

[5] Federal Communications Commission. Spectrum Policy Task Force. Rep. ET Docket n. 02-135, Nov. 2002.

[6] J. Mitola, Cognitive Radio: An Integrated Architecture for Software Defined Radio, Ph.D. Dissertation, KTH, Stockholm, Sweden, Dec. 2000.

[7] S. Srinivasa and S. A. Jafar, "The throughput potential of cognitive radio: a theoretical perspective," IEEE Communications Magazine, vol. 45, no. 5, pp. 73-79, May 2007.

[8] A. Goldsmith, S. Jafar, I. Maric, S. Srinivasa, "Breaking spectrum gridlock with cognitive radios: an information theoretic perspective," Proceedings of the IEEE, vol. 97, no. 5, pp. 894-914, May 2009.

[9] E. Hossain, L. Le, N. Devroye, and M. Vu, "Cognitive radio: From theory to practical network engineering," Advances in Wireless Communications, (Eds. V. Tarokh and I. Blake), Springer, 2009.

[10] R. Taranto, H. Yomo, P. Popovski, K. Nishimori, and R. Prasad, "Cognitive mesh network under interference from primary user," Wireless Personal Communications, vol. 45, no. 3, pp. 385-401, May 2008.

[11] D. I. Kim, L. Le, and E. Hossain, "Resource allocation for cognitive radios in dynamic spectrum access environment," Proc. IEEE CrownCom, 2008.

[12] Y. Kwon, H. Kim, J. Yoo, J. Chung, ”Orthogonal beamforming methodology in cognitive radio networks," Proc. IEEE CrownCom, 2008.

[13] H. Islam, Y. Liang, and A. T. Hoang, "Joint beamforming and power control in the downlink of cognitive radio networks," Proc. IEEE WCNC, 2007.

[14] A. E. Zoogby, Smart Antennas Engineering, Norwood, MA: Artech House, 2005.

[15] J. S. Lee and L. E. Miller, CDMA Systems Engineering Handbook, Artech House, 1998.

[16] H. H. Xia et. al., "Microcelluar propagation characteristics for personal communications in urban and suburban environments," IEEE Transactions on Vehicular Technology, vol. 43, no. 3, pp. 743-752, Aug. 1994. 